\title{
Denegación y límite. Acerca de los llamados trastornos límites
}

RESUMEN: El estudio de los trastornos del límite revela que la neurosis y la psicosis sólo cubren un reducido campo de la psicopatología. PALABRAS CLAVE: Límite, denegación, identificación, ambivalencia, narcisismo.
SUMMARY: Studies regarding disorders of borderline point out that neurosis and psychosis only cover a small field within psychopathology.

KEY WORDS: Borderline, denial, identification, ambivalence, narcissism.

El mundo que nos rodea resultaría desolador si no fuera por el mundo que llevamos dentro.

Wallace STEVENS

\section{Introducción: sobre fenómeno y estructura}

Cualquier estudiante de psiquiatría o de psicología que quiera orientarse por el DSM IV en esta omnipresente y a la vez huidiza patología, encontrará diez distintos trastornos de la personalidad a los que hay que añadir para mayor inri un undécimo llamado «trastorno de la personalidad no especificado», como si los anteriores lo estuvieran. Ya, tal abundancia clasificatoria, con el añadido además del inespecífico, nos indica las dificultades y la complejidad de la tarea empezando por la tarea clasificatoria. Cuando uno lee de un tirón las diversas características que se utilizan como criterios diferenciales, pronto uno ya no sabe de qué trastorno se trata, de tan parecidos y meramente acumulativos que resultan. Está el trastorno paranoide de la personalidad (suspicacia) y el esquizoide (emocional), pero también el esquizotípico (excéntrico), y luego viene el antisocial y el propiamente límite (inestabilidad-impulsividad), a los que se añaden el histriónico (llamar la atención), el narcisista (necesidad de admiración), el inhibido («trastornos de la personalidad por evitación»), el obsesivo-compulsivo y el dependiente.

No quiero detenerme en resaltar lo caótico, inespecífico y forzado de esta clasificación, para la que todo es un trastorno y que cabría entender en referencia a un ideal de normalidad enteramente ficticio (¿quién no se reconocería en esos rasgos, así, echados a voleo?), como lo es el mismo término de «personalidad», comodín que puede servir para nombrar cualquier cosa del individuo y que sólo se puede disculpar porque vino a cumplir en su momento una cierta función epistémica en la historia de la psicopatología que consistía en utilizar dicho término para diferenciar estos trastornos de las dos estructuras clínicas definidas: la neurosis y 
la psicosis. Pero ya se sabe lo que sucede con esos términos provisionales, que la inercia tiende a mantenerlos. El término «personalidad» nunca fue bien definido y se usó como comodín epistemológico abstracto y poco riguroso que lejos de iluminar lo particular, lo oscurece y confunde, desplazando el criterio distributivo hacia una concepción de la normalidad del todo inerte, no sólo ficticia, como digo, por inexistente, sino inerte, un ideal de normalidad en el que no cabría la pasión, ni el pánico, ni el desorden, ni el engreimiento, ni la dependencia, ni la rivalidad, ni el sentido persecutorio (¡como si hubiera otro!), ni el odio ni la súplica. He aquí entonces un ideal de normalidad que más bien parece el epitafio cursi y exagerado de un nicho mortuorio.

En la lección 31 de sus Neue Vorlesungen, Freud compara la psicopatología con el cristal que se rompe según líneas precisas de fractura, quizás invisibles antes de su rotura. Esa sería la estructura del cristal, esas grietas y esas líneas de fractura. Así es, añade, la estructura de la llamada enfermedad mental o Geistkrankheit, la cual de ninguna otra manera podría sernos conocida más que a partir de su fractura. No es mala idea esta de guiarse no por un ideal de normalidad sino por las nervaduras de las quiebras y de las defensas que darían su particularidad estructural al sujeto, cuyas líneas de fractura o grietas irían cristalizando desde el inicio, siendo constitutivas de la encarnadura del sujeto, de su concreción, y que sólo su rotura permitiría ver.

Por eso, la dificultad diagnóstica no se resuelve negando la existencia de tales trastornos por la sencilla razón de que nos topamos una y otra vez con ellos, y podríamos decir que cada vez más. Por lo cual, resulta que topamos con un tipo de «trastornos» respecto a los que no encontramos unos aquilatados modos de inteligibilidad, no por un excesivo afán clasificatorio, o no sólo por eso ni principalmente por eso, sino por ser fenómenos clínicos tan imprevisibles o tan confusos y diversos que se resisten a una mentalidad clasificatoria. De forma que estos trastornos, propiamente fenómenos, que se resisten a una clasificación basada en criterios o proposiciones universales, demuestran que la clínica no se puede basar en tales principios universales, en la autonomía institucional del concepto, aún cuando con ellos se pretenda dar cuenta de la realidad singular, sino en fenómenos, en aquello que se muestra en su realidad diferenciada a la mirada o a la intuición, interrogándonos. El fenómeno resiste en su mostración a su pronta inteligibilidad, y aquello que se resiste a la inteligibilidad de una doctrina es siempre un terreno fértil para hacernos algunas preguntas, quizás no previstas en el guión de la doctrina.

La primera pregunta, la pregunta previa, o si se quiere metodológica, que debemos hacernos es sobre ese aspecto de confusión y de abigarramiento con el que se presenta para el clínico este tipo de fenómenos de tan difícil discernimiento. ¿Esa dificultad responde a nuestra limitación coyuntural para encontrar la 
ORIGINALES Y REVISIONES

buena manera de ordenamiento, o dicha dificultad proviene del mismo fenómeno clínico que intentamos clasificar y que constituye un obstáculo interior al doctrinarismo que en su afán clasificatorio y reduccionista deja fuera demasiada realidad inadecuada a sus criterios?

\section{Estados límites como estados de desvalimiento}

Las Jornadas Interuniversitarias París V-París VII, celebradas en 1998, tenían como tema los estados límites o fronterizos y su título era États de detresse, es decir, estados de vulnerabilidad o desamparo, de desvalimiento, en referencia al término o concepto de Hilflosigkeit con el que Freud venía a referirse a la peculiar condición del infans humano sometido en su desvalimiento a una dependencia que genera angustia y sentimiento de desprotección o desamparo, estado que inicia la particular condición del sujeto humano expuesto nada más nacer a una vida instintiva desordenada o destruida, sin un programa dado de cómo vivir, necesitado de raíz del otro para vivir, con lo que eso incorpora de sentimientos encontrados, de experiencias contradictorias y de continuos anhelos y temores. Cómo valerse en la vida, es una tarea del sujeto y no un programa previo con el que vendría a la vida ya provisto. Pero si algo común del sujeto humano se puede decir es precisamente esta dimensión particular del mismo, ya que al no haber programa de vida previo, se convierte en una experiencia enteramente singular y por ello angustiosa. Lo más común sería así su más genuina particularidad.

¿Por qué esas Jornadas convocan un debate sobre los estados límite como estados de desvalimiento? Quizás por lo que anteriormente dije acerca de la necesidad de abordar estos estados o trastornos desde otras perspectivas que las habituales de la neurosis o la psicosis. Lo que parece fuera de toda duda es que el tal desvalimiento afecta a la particularidad de todo sujeto, independientemente de si puede construir o no una tipología diagnóstica de respuesta, en todo caso siempre insuficiente o nunca definitiva, al silencio del trauma y el conflicto pulsional.

Abordar los estados límites como estados de desvalimiento, ¿querría decir, entonces, que son sujetos sin estructura clínica alguna? Esta fue, como se sabe, la tesis que Jean Bergeret propuso en 1974 (La personalidad normal y patológica). Sería una curiosa estructura clínica que se caracterizaría por lo que llamó «aestructuración» o «estado» en los límites de la neurosis y de la psicosis. Probablemente todos hemos tenido la sana tentación de tomar los trastornos llamados límites como estados de a-estructuración, sin estructura clínica. Quiero hacer al respecto dos anotaciones. La primera es que la estructura clínica se ha de entender como un modo de hablar en el sentido del segundo Wittgenstein, es decir, un modo de inteligibilidad y no un orden conceptual que toma su consistencia de 
la profesión de doctrina. El problema es que, en efecto, hay fenómenos clínicos que no responden a su posible adscripción en la neurosis o en la psicosis, que no responden a las estructuras diagnósticas conocidas, porque ninguna de ellas, ni siquiera la psicosis, da cuenta de la realidad más originaria y particular del trastorno del sujeto, de su torpeza afectiva y fisiológica, de su agresividad, de su miedo. Por eso, este tipo de fenómenos clínicos constituyen una oportunidad extraordinaria para mirar nuestra deplorable situación sin anteojeras, de mirar ese fondo de tristeza y daño habitualmente soslayado.

Hay algo interesante en los trabajos de Bergeret que no reside en su propuesta clasificatoria de una estructura «a-estructurada», sino en que haya podido ver, sin demasiados prejuicios doctrinarios previos, la patología depresiva del llamado «estado límite». ¿Por qué? Porque lo que subraya es la dificultad de estos sujetos para tratar la pérdida, incluso, y esto sería a mi parecer lo más específico, para inscribirla en su vida psíquica, lo que les conduce a una dependencia anaclítica que no soporta la separación y que es, sin embargo, un rasgo permanente de la misma condición del sujeto como tal sujeto.

\section{Angustia de separación e «identificación proyectiva»}

Esto nos ayuda a entender una angustia de separación, por utilizar la expresión freudiana, que nos hace indefensos y asustados, y, por ello, peligrosos, carentes de la kantiana «conciencia del otro», sin la cual no hay distancia libidinal que permita una estrategia del deseo, ni tener conciencia o experiencia siquiera de la realidad separada del otro. La angustia de separación detiene al sujeto en su intento de negación, ante el abismo que esa negación abre, como si no existiese ninguna otra cosa que la nada de la distancia de la consciencia, el vacío y la soledad de la separación que engulle y anula el movimiento. Eso les da ese aspecto de irrealidad, o directamente de falsedad, a lo que hacen o a lo que sienten.

De ese no poder abordar la soledad de la pérdida y crear así un espacio subjetivo, es de lo que ha pretendido dar cuenta a lo largo de los años el concepto de origen kleiniano de la identificación proyectiva, es decir, al no haber una distancia subjetiva, la confusión con el otro es habitual y los propios contenidos psíquicos, cualesquiera que sean, fantasías, emociones o temores, se proyectan en el otro, como si carecieran de intimidad propia, sin apercibirse de la existencia real si no es como mero reflejo de temores persecutorios o idealizaciones anaclíticas. El terror a la omnipotencia de ese otro arcaico, figura materna del poder, impide la distancia y la disponibilidad para atender la precariedad de un sujeto marcado por sus identificaciones y sus pérdidas concretas. 
ORIGINALES Y REVISIONES

Las tesis freudianas sobre la identificación no dejan de plantear sus contradicciones, a veces por la confusión entre identificación e idealización y otras por hablar de una identificación arcaica o primitiva, no sólo «anterior a toda elección de objeto», como dice en esa lección 31, sino correlativa a la «incorporación oral». La «incorporación oral» puede ser una sensación, pero de difícil o confuso contenido; experimenta y es, a mi parecer una manera demasiado confusa de referirse a esa figura de terror y de omnipotencia, con la que no cabe identificación posible sino parálisis, inmovilidad psíquica. Para poder tener representación psíquica se requiere una identificación y, por tanto, una separación. Resulta forzado hablar de una identificación indiferenciada, sin sujeto de ese objeto. En lo que sí estoy de acuerdo es en que la identificación es anterior a la elección de objeto, pues sería su condición, pero lo es precisamente por lo que Freud tantas veces señala como rasgo fundamental de la identificación: la pérdida del objeto. No hay elección posible sin la inscripción psíquica de la pérdida, sin la inscripción de esa experiencia. Pues bien, si no hay identificación sin la experiencia de la pérdida, como repite machaconamente, no entiendo cómo se podrían aunar ambos términos: «identificación»-«proyectiva», ya que lo proyectivo en todo caso, si se toma en sentido estricto, es contrario a la identificación, la cual es efecto del rastro o marcas de las pérdidas que fraguan la vida y que se inician con las tempranas experiencias de satisfacción y de dolor en relación con la figura de la madre, y no con la pertenencia grupal. No es que lo que se quiere nombrar como identificación proyectiva no se dé, pues es habitual observar cómo uno ve al otro no como alguien distinto sino como una pantalla sobre la que se proyectan los propios anhelos y, sobre todo, los propios temores. La proyección es un modo de construir una escuálida escena fija, una especie de representación sin desplazamiento, pero de afecto amortiguado, como si a falta de universo psíquico interno se intentara pergeñar una escena que opere como código de una interpretación reiterativa, pero fija, del otro, para que así la angustia pueda respirar.

La proyección, por tanto, sería más bien efecto de una fragilidad identificatoria, de un mimetismo adhesivo y, en suma, un efecto de la angustia de separación (Trennungsangst), lo que impide aclarar las pérdidas y prefiere entonces acompañarse de ese escueto ruido interpretativo que crece paradójicamente a medida que el sujeto se resiste a desaparecer en esa escena fija. Y de ese modo, su propia anulación le conduce a adecuarse a una interpretación mecánica, automatizada, o en general a un comportamiento adictivo, en una especie de círculo infernal que necesita, como luego veremos, la denegación o modo de no enterarse de dónde anda metido.

Esa mezcla de proyección «maníaca» (como si se supiera todo del otro) y desvalimiento depresivo, es lo que llevó a Bergeret a tomar la psicosis maníaco-depresiva, los tan traídos y llevados y, por tanto, abusados, trastornos bipolares, más del 
lado de los trastornos límites que de la psicosis propiamente dicha. Es cierto que una esquizofrenia, por ejemplo, se parece poco a una psicosis maníaco-depresiva o a un trastorno bipolar. Pero creo que sería un error confundir la psicosis maníacodepresiva con los trastornos del limite, no sólo porque el delirio maníaco es un delirio que crea un mundo externo donde el sujeto intenta localizarse (participa tanto de la persecución como de la filiación que constituye el fondo argumental de todo delirio), sino también porque no se puede entender la melancolía como falta de vida interior. Un melancólico especialmente advertido me explica que la falta de vida la siente «como mancha moral que sólo se podría reparar con un amor de dedicación». Entiende el «amor de dedicación» como la entrega total e incondicional a otra persona como forma de vida. Pero, añade, «la misma falta de vida impide el amor». Estas palabras indican un tipo de intimidad que no se encuentra en los trastornos del límite. Es de agradecer, de todos modos, el que Bergeret insistiera en ese fondo depresivo del «estado límite», pues, en efecto la precariedad del sujeto, la angustia invasiva y asfixiante ante la separación, y el tipo de dependencia, sea manipuladora o simplemente adhesiva, da esa tonalidad desvitalizada y que hace tan dependiente como insensible. Más adelante abordaré la cuestión de lo absoluto y la creación de un mundo perceptivo (alucinatorio y delirante) en la psicosis en contraposición al trastorno del límite.

\section{La cuestión del límite o límite como concepto}

Pero antes veamos algunas cuestiones terminológicas, ¿por qué a este tipo de trastornos se les llama «límites»? Permítanme un pequeño recorrido por esta cuestión del límite en la vertiente que a nosotros más nos puede interesar. Límite es un concepto clave del pensamiento moderno desde Kant, quien frente a la idea de un orden finalista, universal y cosmológico, introduce el concepto de límite interno. No les voy a aburrir con un estudio que sería, por otra parte, apasionante, sobre el concepto de límite en Kant o en Leibniz, etc. Trato simplemente de establecer las mínimas referencias. ¿Qué es posible conocer?, ¿qué cabe esperar?, ¿qué se puede hacer?, son las tres preguntas kantianas que reorientan el pensamiento hacia el hombre, hacia el sujeto del conocimiento y de la acción. Hay un límite gnoseológico que da al conocimiento su rigor a la vez que su limitación, y hay un despiste moral en el hombre que le lleva al conflicto de no coincidir nunca con lo que debería, por lo que la «disposición al bien» va ligada a su molestia moral ante el daño padecido y producido. Y no hay sujeto propiamente dicho que no posea esa desazón moral.

La raíz de todo eso habría que buscarla en el lugar del hombre en el mundo. La última obra de Kant -cuatro años antes de su muerte- es la Antropología desde 
ORIGINALES Y REVISIONES

el punto de vista pragmático; con ese título Kant, después de sus detenidos análisis sobre la autonomía de la Razón, quiere referirse al estudio del hombre concreto, singular, no desde el punto de vista metafísico o fisiológico sino pragmático, es decir, de quien obra y actúa a partir de su extravío de la naturaleza, o de cómo podría el hombre gobernar la patología de sus pasiones, que no es otra que la que proviene de su desregulación como viviente. No nos interesa su psicopatología, de lo que también escribió, sino ese punto de partida que supone la indagación, la pregunta sobre el lugar del hombre en la naturaleza, ese lugar fronterizo, que es tanto su precariedad como su particularidad productiva y espiritual. El hombre es creador de lo bello (modo de dar forma, de crearla a partir de la materia informe, siendo entonces su vida una tarea creativa, formativa, en suma, ética), y víctima de lo sublime como el abismo que se abre por su lugar fronterizo entre la naturaleza y el espíritu. La obra de arte es bella y establece un juicio concreto sobre un producto concreto, pero «el inmenso océano enfurecido» o «el cielo amenazador donde se juntan las nubes de tormenta», es sublime, por el lugar reducido, precario y fascinante a la vez que viene a ocupar el hombre en esa inmensidad natural que siempre le sobrepasa.

El hombre está sobrepasado, será una tesis esclarecedora de la antropología de Arnold Gehlen. Al ser el sujeto carencial, incompleto y defectuoso, a la vez que viviente, está siempre sobrepasado por la vida, la vida es siempre excesiva, dada la falta de recursos para saber qué hacer con ella. Por un lado, la carencia de objeto adecuado a su satisfacción, y, por otro lado, el exceso, el sujeto surge así en el límite de la carencia y de su condena a actuar sin saber cómo. Actúa no hacia algo, no para alcanzar algo, que es lo que había propuesto el optimismo kantiano, sino para defenderse de algo, de ese enemigo interior que es como llamaba Freud al exceso pulsional, a la insatisfacción pulsional. La defensa rige la acción del sujeto, por eso no actúa para algo sino contra algo, lo que convierte a la acción en una necesidad. Hay un círculo infernal entre insatisfacción-acción-satisfacción-insatisfacción, en el que la acción es el eje de esa noria. Esa condena a actuar es lo que hace al hombre tan peligroso, se junta, se compincha para actuar, y nosotros que hablamos de pasos al acto o de «exoactuación» deberíamos ser menos estrechos y mirar cómo el mundo en general es una locura de pasos al acto. La política de hoy es, por ejemplo, sólo eso, pasos al acto defensivos y reactivos, es decir, verdaderamente peligrosos, sin límite ni rigor internos y, por tanto, sin la más mínima orientación, como si la consigna de «ienriqueceos!», fuera una ley natural.

El sujeto vive en el límite y del límite, entre el rechazo y la dependencia, es decir, vive en el miedo. El objeto transicional de Winnicott es el modo que encuentra el niño para protegerse de un mundo, de una realidad completamente extraña que le sobrepasa. El origen de esta extrañeza es su distancia del instinto. El instinto no gobierna la vida de los hombres, que siguen siendo, sin embargo, anima- 
les. La pulsión es el nombre de esa distancia del instinto, de ese exceso y de esa ineptitud para vivir que le hace precario y dependiente del otro, por lo que también se puede decir que la pulsión es el nombre de esa marca del otro en el cuerpo, la marca de una extrañeza y de una dependencia cuya mezcla le hace tan temeroso.

\section{Pulsión y límite: límite y conflicto}

Freud define la pulsión como «concepto límite entre lo somático y lo psíquico». Recoge así el concepto de pulsión de la antropología filosófica alemana que lo había inventado para explicar la particular condición del hombre, como extravío y pérdida del instinto. Freud lo recupera para la clínica $p s i$, descubriendo que la pérdida de naturaleza que padece el hombre opera como pérdida del otro, de su protección, aparece en consecuencia como temor al abandono o angustia básica de la que nadie se libra, esté entre algodones o a la intemperie.

Esta idea de límite conlleva la de escisión, o condición fronteriza, y la de conflicto entre el empuje a la vida y el empuje desesperado a la destrucción, entre el rechazo y la dependencia, entre el deseo y los obstáculos de dependencias anaclíticas (en las que el cuerpo y el otro andan confundidos), entre el sujeto y el otro, entre el objeto de la satisfacción y el sujeto del deseo (conflicto intrínseco a la satisfacción humana y que liga tan estrechamente satisfacción y Versagung o decepción), conflicto finalmente entre amor y odio. Este asunto es vital para una clínica que trata de la articulación conflictiva de los sentimientos y de las representaciones del otro, y que es especialmente de interés en el caso de los llamados trastornos límites, porque por lo que llevamos dicho se ve que el sujeto humano es un ser fronterizo que vive en el límite, en permanente inadecuación tanto en su condición de viviente como en su afán institucional. Y construir modelos de normalidad es un modo de desentenderse. Desentenderse es, precisamente, una habitual defensa en los llamados trastornos límites, y no sólo en ellos, desentenderse o no poder encontrar alguna manera de entenderse con el conflicto pulsional entre conservar el objeto o destruirlo, y así uno se asusta de su desorden sentimental y pulsional.

La pulsión, según la definición freudiana, es un «concepto límite» entre lo somático y lo psíquico, señala, por tanto, es lugar fronterizo del hombre, su extravío como viviente y lo que Gehlen llamó 'exceso pulsional' (Antriebüberschuss) o desmesura de la insatisfacción por carecer de objeto adecuado. Eso empuja a la confusión, al desorden y a la agresividad. La pulsión es un conflicto que requiere para su tratamiento un límite interno que cree un espacio subjetivo, una distancia del otro. Eso es la vida inconsciente. El inconsciente es el límite interno de la pul- 
ORIGINALES Y REVISIONES

sión, lo que la vida inconsciente lleva de deseo, a partir de la insatisfacción, y de demanda amorosa, a partir del desamparo. Pulsión e inconsciente son, digamos, los dos conceptos claves de una clínica del sujeto, que trata de los avatares que acontecen entre el cuerpo y la dependencia vital del otro. Adelantaré que en nuestra práctica observamos que no hay, precisamente, experiencia subjetiva o posibilidad de cambio más que a partir de que el sujeto se vea en conflicto moral con lo que hace, que lo que hace le produce un conflicto moral con los demás. En la clínica de los trastornos del límite es ineludible perseguir esta aparición del conflicto, única posibilidad de rectificación subjetiva.

\section{¿Trastornos límites o trastorno del límite?}

De ahí el interés de la distinción entre límite externo y límite interno, ya que sólo el límite interno permite tomar al otro como sujeto y, por tanto, tener la experiencia del conflicto. Por eso, lo que se llama trastornos límites, sería más bien, y quiero subrayarlo, trastornos del límite, porque el límite no sólo es una contención exterior al sujeto, sino, como vemos, una distancia, un espacio de intimidad que permite, que es incluso la condición sine qua non para encontrarse con los demás. Querer algo de ellos, es requisito para poder pedir y poder perder. Decía el poeta Wallace Stevens: «El mundo que nos rodea resultaría desolador si no fuera por el mundo que llevamos dentro». No podríamos vivir sin ese mundo interno. Esa intimidad de la vida inconsciente, esa distancia, es una disponibilidad, pero es también orientarse por la soledad de un deseo propio y no tanto por el daño. El conflicto pulsional, el desbarajuste presente en nuestra relación con los demás, la ineptitud del sujeto para la vida, sólo admite enderezarse por un deseo propio que no es que quite los temores, pero disminuye su absolutismo.

El límite interno crea una distancia del otro que despeja la confusión y la insensibilidad. Por eso insisto en llamar a estos trastornos «trastornos del límite» en vez de «trastornos límites». También lo absoluto es un ataque al límite interno. El absolutismo psicótico, por ejemplo, efecto del fracaso de la represión y del desplazamiento, de la metaforización que quita al lenguaje su tentación de absoluto, toma la subjetividad del otro como si fuera absoluta y el sujeto se ve obligado a crear una trama delirante donde no sea aniquilado aunque todo el tiempo esté amenazado de ello. El sujeto psicótico vive de ser amenazado, se mueve entre el designio absoluto de filiación y el terror persecutorio de la subjetivad del otro, amenaza de la propia. El empeño de Schreber era el de reducir lo más posible la subjetividad de Dios. El psicótico no cree en Dios porque soporta su existencia. Los demás creen en Dios porque no existe. Nadie cree en lo que existe sino en lo que no existe. En realidad, el trueque de una inmortalidad a cambio de un Dios absoluto, produce 
mucho más temor que consuelo. El sujeto no soporta a Dios por mucho que lo necesite, sólo lo soporta el sujeto psicótico. Dios, como la muerte, es una figura de terror más que de consuelo. La necesidad de lo absoluto conlleva la amenaza de la aniquilación del sujeto a cambio de un continuum que desplaza el límite eternamente. Pero el límite está en la subjetividad misma, es un corte, una quiebra con el continuum, por ejemplo, del instinto. De ahí que sólo hay muerte para un sujeto, como ya explicaba el poema de Goethe.

Esa quiebra obliga al viviente humano a regirse por un deseo finito, pero propio y cambiante en correspondencia con la brevedad de la vida. He dicho anteriormente que el inconsciente es límite interno a la insatisfacción pulsional. Ese límite se nombra como deseo o límite al empuje pulsional, pues no hay otro modo de limitar el empuje pulsional, su inadecuación, más que con la distancia subjetiva del deseo. Eso es especialmente complejo a causa de las defensas construidas en torno a la angustia de separación y al miedo, que convierte la ausencia y la distancia en abandono. Ahí no actúa la represión como operación de desplazamiento y de separación. No hay separación entre la representación y el afecto, luego no hay desplazamiento ni metáfora, condición de la diversidad de la existencia del otro, ni hay, por tanto, límite interno. El límite interno opera precisamente desde su discontinuidad, a diferencia del límite exterior que se establece para definir la barrera del continuum. Sería la diferencia entre Grenze (propiamente 'límite') y Schranke ('barrera'). Puede servir como ejemplo el debate acerca de cuándo se puede interrumpir el embarazo. No hay salida sin la convención de un límite externo. Habitualmente, también se encuentra ese criterio en los manuales de psicopatología. ¿Cuál es el criterio diferencial de una u otra normalidad o psicopatología? Con frecuencia el exceso. Está, por ejemplo, el depresivo mayor o mayormente triste o excesivamente triste, y está el excesivamente ansioso, etc. Lo que podemos llamar imperialismo diagnóstico, sería un modo de usar la clasificación como límite externo para contener la angustia del profesional ante el fenómeno clínico.

En esto de los trastornos del límite, su carácter fronterizo ha llevado a definirlos como ni una cosa ni otra, ni psicosis ni neurosis o ambas cosas: un mixto de síntomas psicóticos y síntomas neuróticos. Esta es una concepción del límite exclusivamente exterior por aplicación de criterios diagnósticos exteriores al cuadro propio de los llamados trastornos límites, que por lo dicho anteriormente, habrá que llamar definitivamente trastornos del límite, ya que en tales sujetos lo que parece comúnmente aceptado es que al no haber elaboración no aparece un límite claro entre lo interior y lo exterior, entre sí mismo y el otro, en todo caso es lo que yo estoy tratando de definir como falta de espacio interno libidinal y de vida inconsciente, frente a la muerte interior, característica a mi parecer de estos trastornos del límite o de la falta de límite interno que cree distancia con la subjetividad del otro y posibilite así una percepción de él no meramente atributiva sino en 
ORIGINALES Y REVISIONES

su distante y concreta existencia y, por tanto, en su complejidad subjetiva y pulsional, etc., como alguien que ama y odia, que busca y rechaza, alguien parecido a uno mismo al menos en sus dificultades con la vida. Sería semejante a lo que los kleinianos llaman escisión del objeto. Ellos utilizan el término escisión en contraposición a integración y objeto total. Es un lenguaje o una terminología que no me gusta porque una vez más parece suponer un modelo de normalidad basado en la integración y en la reparación. Quiero señalar que subjetividad e integración se contraponen, pues el sujeto es de por sí inadaptado, incompleto y contradictorio, y que la reparación consiste en mantenerse en el dispositivo fantasmático, es decir, sadomasoquista, del poder, ya que el empeño en reparar lo acaecido suele suponer el rechazo de las consecuencias de su acontecer y, por consiguiente colocarse, como diría Benjamin, en el campo del vencedor y de la necesidad de victoria.

Sin embargo, creo que la clínica que subyace en esa terminología acierta al concebir el «objeto total» como aquel que admite ambivalencia, contradicción y que integra lo bueno y lo malo en vez de escindirlo «esquizo-paranoicamente» entre el objeto malo persecutorio y el objeto bueno ideal. Eso, sin duda, apunta a fenómenos clínicos que se ven y a lo que Winnicott expresó como objetivo de un análisis: crear la capacidad de soportar la ambivalencia, la soledad, la finitud y la separación, lo que en el argot psicoanalítico se suele llamar soportar la castración. En ese sentido, se puede decir que en los trastornos del límite no sólo no existe esa capacidad de soportar la ambivalencia, sino que ni siquiera se podría hablar propiamente de ambivalencia. Si el psicótico, debido a su absolutismo, no soporta la ambivalencia, en el trastorno del límite la ambivalencia es borrada por la denegación de la subjetividad del otro.

\section{La cuestión del diagnóstico diferencial}

Antes de entrar en el asunto de la ambivalencia, intentemos responder a la pregunta: ¿constituye o no una estructura y qué rasgos entonces la definirían? En el campo psicoanalítico, los «estados límites» surgieron y fueron desarrollados, sobre todo, por la corriente kleiniana, puesto que en dicha concepción el proceso de formación del sujeto pasa por «estados psicóticos precoces» y la forma de salir de esa «psicosis arcaica» marcará la particularidad estructural del sujeto, aunque no de manera constante o inamovible, ya que cualquier situación que activa la regresión, de manera destacable la transferencia analítica, va a hacer surgir estos estados psicóticos esquizo-paranoides arcaicos. El diagnóstico diferencial residirá en el tipo de funcionamiento predominante. El «estado límite» sería entonces un estado de indefinición como tal estado. Esta era la idea, por ejemplo, del psicoanalista A. Stern, que ya en 1938 habló de borderline cases, como casos de sujetos 
que no pertenecen propiamente ni a la psicosis ni a la neurosis. Anteriormente, ya en 1932, Glover quiso situar la clínica de las toxicomanías como forma intermedia entre la posición esquizo-paranoide y la posición depresiva. Pero el primero que creo que habló de estados límites fue Knight en 1953, con la idea de construir un cuadro de la particularidad de dicho estado. Los rasgos que va colocando eran conocidos: la fragilidad del yo, el predominio de los impulsos pulsionales desintegradores, el vacío interior (por lo que se pide a la realidad exterior que lo supla, idea sin duda de especial interés), el bloqueo ocasional, afectos inapropiados, dispersión de la atención y del pensamiento, significaciones paranoides y a veces trastornos del lenguaje. Su descripción era excelente y toma como eje el concepto freudiano de «yo débil» (que nada tiene que ver con el sentido enteramente arbitrario que luego le daría Lacan), es decir, de un déficit de distancia subjetiva, de espacio íntimo. Ahí ya se puede ver que la descripción de tales fenómenos clínicos apunta a una tipología que admite, sin embargo, ilustrar y mostrar aspectos de la misma condición del sujeto y que, por ello, nos resuenan a cada uno, más allá de la adscripción diagnóstica.

Desde entonces se ha escrito mucho, siempre en esta línea de situar un cuadro diagnóstico preciso y, sobre todo, mínimamente estable. La insistencia en volver sobre estos casos se debe también a su aumento. Cada vez nos encontramos más este tipo de patología o trastorno que se presenta sobre todo por su inaccesibilidad terapéutica. Su pobreza psíquica, su insensibilidad, su fondo melancólico inabordable, sus pasos al acto, su superficialidad afectiva, su inmovilidad, su escasez de recuerdos, que hace pensar en una falta de experiencia subjetiva y en un desvalimiento improductivo, son rasgos cada vez más frecuentes, en cuya frecuencia interviene el tipo de sociedad, hoy día totalmente predominante y de la que para lo que ahora nos interesa podemos destacar algunos rasgos como son: la superficialidad de la información, la imposibilidad de tener experiencia del acontecimiento, la militarización del consumo, el miedo difuso y omnipresente a perder el paso de una manera de vivir colectiva basada en la posesión, la pasividad ante las informaciones recibidas, la homogeneidad superficial, la falta de una moral que no sea un mandato de éxito y, por otro lado, necesitada de recuperar un sistema de buenos y malos, con lo que eso implica de xenofobia y fanatismo, más o menos encubiertos, y de regreso a lo tribal ante la impotencia para actuar y tomar decisiones, y ante la disolución de la distancia íntima. En nuestro ámbito cabría añadir la sustitución del sentimiento y del afecto por la cognición.

Horkheimer y Adorno escribieron hace años que el miedo más propio del hombre contemporáneo era «el temor a la pérdida del yo y la consiguiente anulación de la frontera entre uno mismo y el resto de la vida» (Dialéctica de la Ilustración, p. 86). Es un modo de expresar el pánico al aislamiento, el pánico a ser destruido por los otros en esa crueldad de la vorágine social que hace que el 
ORIGINALES Y REVISIONES

individuo sólo exista por el miedo a perder, a no ser reconocido, a dejar de existir para los demás, a ser aniquilado por los otros, miedo que el poder, falto de otros argumentos, explota hasta el aburrimiento con indudable y cruel eficacia. El héroe moderno, como ha señalado entre otros Carlo Mongardini, no es el trágico griego ni el descubridor decimonónico, sino el héroe de la evasión, el actor de cine o la princesa $X$, no el que descubre y enfrenta la realidad sino el que ayuda a escapar de ella, a ignorarla, a desentenderse de ella. En este panorama, los llamados medios de comunicación han adquirido una importancia capital. A ellos se adjudica y ellos se atribuyen la misión de impartir doctrina reduccionista de todo tipo, científica y moral, dicen lo que hay que pensar cada día y en cada momento y lo que hay que saber para el consumo diario. No queda tiempo para más, no hay tiempo para decidir ni para saber. De ahí que tanto el periodismo como la ideología genetista se hayan convertido en alimento indispensable para la pereza científica y moral. Ambos nos dan un saber reducido a la mínima expresión, un saber reduccionista que actúa como veneno y antídoto de una sociedad apresurada, ignorante y «exoactuadora», para así guarecerse en la simpleza ante su complejidad y, sobre todo, ante su confusión. Saber epidérmico e insensibilidad, son las dos formas con las que enfrentar la complejidad de informaciones y la presencia del dolor más insoportable que muestran los telediarios.

El temor a perder el sentimiento yoico y la consiguiente anulación de la frontera (Grenze: 'límite') entre sí mismo y el resto de la vida, es el pánico del que hablaban Adorno y Horkheimer, y puede ser una buena formulación de los trastornos del límite. A veces ni siquiera ese temor arranca al yo de su confusión perceptiva y sentimental. Por eso resulta sorprendente que Otto Kernberg, en su, por lo demás, interesante artículo «La vivencia subjetiva del vacío», termine diciendo que nada tiene que ver el tipo de sociedad y lo que él llama la «cultura juvenil» con ese retraimiento y difusa ansiedad que caracteriza la relación del joven «narcisista» con los demás. Pero ya el hecho de subrayar la «relación objetal» (que yo prefiero llamar relación con el otro, pues no hay relación objetal pura, ya que la relación se refiere siempre al otro, el cual posee el permanente malentendido de ser a la vez objeto y sujeto), pues bien, si hablamos de relación con el otro, eso debería hacerle más cuidadoso o riguroso a la hora de hablar de cultura y sociedad. Es cierto que un tipo de sociedad no hace de por sí una determinada patología o trastorno, pero simplista y unilateral sería no abrir la reflexión sobre los modos de lazo social a la hora de entender los trastornos que fuere y que muestran a un sujeto cuyo desvalimiento como sujeto le hace del todo social, volviendo una y otra vez a los demás, dependiente radical del otro. Este ha sido siempre un debate de interés especial, por ejemplo, en el caso de la anorexia.

No creo en el inconsciente colectivo, sería una contradicción in terminis, pues el inconsciente es ese espacio íntimo y particular de elaboración y de trata- 
miento del conflicto pulsional. Pero cada sujeto se construye con el discernir y elaborar su conflicto pulsional, ese conflicto entre su cuerpo viviente y el otro, a partir de los modos y argumentos con los que se construye la vida colectiva. Pues bien, en el caso de los trastornos del límite, el tipo de sociedad promotora del individuo y a la vez destructora de la intimidad y de la subjetividad, constituye un marco que favorece la pobreza de recursos psíquicos y de encuadre para tratar el desvalimiento traumático de cada uno. Los rasgos que acabo de señalar de este tipo de sociedad, creo que resaltan suficientemente su común parecido con los trastornos del límite, de manera que su descripción sería intercambiable y, por ello, asignable al sujeto en cuestión.

Pero volviendo al asunto del diagnóstico diferencial, hay que tener en cuenta dos cosas. Lo primero es que este tipo de fenómenos ha modificado, como dije más arriba, la militancia diagnóstica. Dicho cambio permite tratar las líneas de fractura de las que hablaba Freud, como lo que son: modos de defensa de uno u otro tipo que, a partir de determinados avatares, muestran su fragilidad y, por consiguiente, su línea de fractura. Como esa línea de fractura tiene que ver con las defensas ante la condición traumática de cada uno, habrá que ver entonces lo que las debilita. La tesis que aquí propongo es la nula o frágil operatividad de la represión inconsciente y, por tanto la falta de vida inconsciente, lo cual dificulta la creación de un mundo íntimo que establezca una distancia subjetiva con el otro. Eso da el rasgo de inestabilidad. La exposición traumática busca la defensa de la insensibilidad a partir de la denegación. No querer enterarse, como si no pasara nada, es demasiado común. Para que este rasgo tan común pueda figurar como rasgo diferencial, hay que pensar más en un modo de predominio que en una estructura inamovible. Otra clínica, una clínica más libre y concreta y menos referida al diagnóstico, es lo que estos fenómenos exigen.

Esos rasgos de inestabilidad y de insensibilidad siempre se han tenido en cuenta, desde el famoso «como si» de Helen Deutsch, hasta esa especie de sentimiento de irrealidad, que el verborréico Millon expresaba diciendo que tales sujetos se sienten como espectadores de una película, como si no formaran parte de la realidad, estando adheridos, sin embargo, a ella, sin distancia subjetiva con ella, sin vida interior. Y en realidad el ejemplo de Millon no me parece del todo adecuado, pues no es el sujeto mero espectador sino que ese sentimiento de irrealidad le angustia, y como decía una joven apesadumbrada, cuando ese sentimiento le asalta de manera tan desoladora ha de nombrarse y decir en voz alta que es fulanita de tal, hija de tal y cual, que trabaja en tal sitio, etc., para así oxigenar la asfixia que le produce el sentimiento de irrealidad. Si el neurótico habitual parece torturado por sus pulsiones vividas como conflicto moral, y el psicótico crea un espacio íntimo aunque autorreferencial a costa de la realidad colectiva que ha de reconstruir con el delirio, este otro puede tener un trato con la realidad sin distancia interior, lo 
ORIGINALES Y REVISIONES

que produce, con frecuencia, pequeños y puntuales esbozos delirantes que no son más que intentos de crear un nudo fantasmático, una representación psíquica con la que poder interpretar el mundo. Esto debe entenderse en relación con la tan traída y llevada labilidad yoica, que para mí consiste en que a falta de una escena interior construida, se llame fantasma o fantasías inconscientes -en todo caso espacio libidinal interno o capacidad para fantasear y tener conciencia de los propios sentimientos-, construye esbozos abortados de fantasías mostrándolos o proyectándolos en el exterior. Yo prefiero no usar el término «proyección», porque no es algo interno que se pone fuera, sino que es un interno no construido que se intenta construir con elementos exteriores, lo que da ese aire alucinatorio, sin que se consiga una diferenciación o límite interior/exterior preciso.

Tampoco es la reconstrucción de realidad que lleva a cabo el sujeto psicótico desde su desconexión. Estos otros sujetos están en la realidad, pero al carecer de espacio interno es como si no tuvieran experiencia subjetiva de esa realidad. Repiten comportamientos e ideas fijas que no consiguen ni una interpretación del otro ni una construcción, lo que les hace especialmente inermes (el acierto de las Jornadas universitarias celebradas en París en 1998 fue precisamente subrayar este aspecto de desamparo e indefensión). Construyen escuálidos maniquíes que no les permiten una dimensión en profundidad con la que fantasear un escenario sentimental. De ahí, por ejemplo, que en su relación afectiva no se haya construido una escena amorosa de amor correspondido. No aman, pero tampoco se representan el ser amado. Para esa escena es requisito la distancia y la pérdida, y por tanto la ausencia, en suma, la experiencia de la vida. El que la vida esté sometida a experiencia quiere decir que nadie puede ser suplido a la hora de vivir, nadie puede sustituir a nadie en la vida, lo cual adquiere una tonalidad temerosa cuando se siente ese miedo, del que hablaban Adorno y Horkheimer, a ser destruido como sujeto. El sujeto viviente no puede ser suplido, pero puede ser destruido, acosado o intervenido por el miedo.

\section{Pérdida de percepción versus pérdida de amor}

En el Apéndice a Inhibición, Síntoma y Angustia, en el apartado sobre «Angustia, deseo y tristeza», decía Freud que la primera condición de la angustia es la pérdida de percepción, que se equipara a la pérdida de objeto y añadía: «No entra todavía en juego la pérdida de amor». La pérdida de amor entra en juego más tarde, una vez que la experiencia subjetiva del otro introduce la ausencia y la conservación amorosa interna. Pero la primera pérdida es la pérdida de la percepción del objeto, una primera pérdida que da lugar a la representación y al pensamiento como muestra el juego freudiano del fort-da. Es el comienzo del discernimiento. 
En el siempre interesante artículo de 1925, Die Verneinung ('la negación'), establece como condición del discernimiento mental el que «se hayan perdido objetos que antaño procuraron una satisfacción real». La precisión freudiana es interesante: 1) la pérdida del objeto es condición de la representación psíquica; 2) esa pérdida debe ser de una satisfacción real para que exista al menos la posibilidad de una inscripción inconsciente de la pérdida y capacidad, por tanto, de duelo. No hay ausencia si previamente no hay presencia.

El que en estos sujetos a los que nos estamos refiriendo, exista esa especie de fisicalismo de la presencia, una adhesión perceptiva, no por su constancia menos epidérmica, quizás nos está indicando que es un tipo de presencia que no creó un vínculo que pudiera luego sostenerse en la intimidad de la ausencia. Cuando esto sucede, cuando la relación con el otro se juega por entero en el campo perceptivo, sin que haya inscripción de la ausencia o falta del otro, el otro es objeto y su condición de sujeto se ve velada por el lugar persecutorio que se le da. El sujeto queda reducido a objeto bajo la mirada del otro, y entonces la angustia le paraliza. Sea que el otro es objeto desvalorizado u objeto persecutorio, el sujeto es mera angustia al no tener otra existencia que la de objeto inerte, inmovilizado. Esa angustia es paralizante e insoportable, y sólo le queda empujar en la dirección de la «exoactuación», del paso al acto compulsivo y violento. ¿Cómo tratar con el otro si la dimensión subjetiva no está en juego? No hay trato, sólo manipulación o temor.

No es del todo sorprendente que pueda haber sujetos, por ejemplo, con manifiesta capacidad profesional y mental, incluso con una cierta capacidad de manipulación, y que tengan, sin embargo, tanta carencia y torpeza afectivas a la hora de preservar y conservar a las personas queridas, sin buscar exclusivamente su mortífero dominio o su presencia inerte. Quizás la frase que añadía Freud a propósito de la pérdida de percepción del objeto sea esclarecedora: «todavía no está en juego la pérdida de amor». Es una frase que al leerla puede sorprender, dada la capital importancia del vínculo afectivo en la representación psíquica, pero nos indica que la pérdida de percepción no es lo mismo que la pérdida de amor, por lo que una capacidad de representación mental, que se basa en la pérdida de la percepción del objeto, no es, sin embargo, lo mismo que el espacio íntimo en el que se construye la escena amorosa, en la cual el otro adquiere una distancia y una existencia subjetiva que no tiene en la primera representación mental, donde era sólo objeto de adhesión pero meramente perceptivo.

Por esa razón podemos encontrarnos con sujetos con claro rendimiento intelectual o artístico y, sin embargo, con una pobreza afectiva y sentimental que con frecuencia es a su vez soporte de su rendimiento intelectual. El saber y el crear pueden ponerse al servicio de la denegación, de no querer saber ni enterarse de sus movimientos pulsionales, de su sinsentido y de su angustia. Sería un modo de 
ORIGINALES Y REVISIONES

«suprimir» el afecto por medio de la sublimación, es decir, un modo de usar la pulsión por fuera de su condición sexual y corporal, para así contener la agresividad.

La cuestión no es, entonces, la capacidad mental sino la capacidad de elaboración psíquica, la capacidad de amar, si se prefiere, o de sensibilidad. Cuando del otro sólo cuenta la presencia física y perceptiva, la capacidad mental suele verse reducida a las relaciones de poder, de captación y control físico. En los cada vez más frecuentes casos de malos tratos e incluso de asesinato de mujeres por parte de sus «parejas» o «ex-parejas», suele estar presente este tipo de angustia primitiva ante la pérdida de la percepción y del control físico que a falta de sublimación conlleva una sorda agresividad que empuja a la violencia. No es la pérdida del amor lo que está en juego sino el terror ante la pérdida del mero objeto de la percepción, de la posesión perceptiva. Sin él, como sucede en el niño más pequeño, la angustia ante la separación es una angustia de muerte. Como diría M. Klein, no se da la posición depresiva, es decir, el acceso a la ambivalencia, a la realidad contradictoria del otro, viéndose así reducida la distancia entre lo interior y lo exterior, entre el espacio íntimo y la representación de lo exterior. No hay amor sin la existencia separada del otro.

\section{Amor e inconsciente}

La distinción freudiana entre ambas pérdidas, la de la percepción y la del amor, adquiere entonces interés para abordar estas cuestiones, dado que, y es lo que quiero subrayar, la segunda supone capacidad de elaboración inconsciente de la pérdida del objeto amado, de su ausencia, no como signo de abandono o de destrucción sino como distancia o pérdida. El inconsciente conserva la experiencia de huellas o marcas de lo vivido, del dolor y de la satisfacción perdida, de lo temido y de lo anhelado, del odio como rechazo y del amor como búsqueda, del desconcierto y de los límites del sentido, es decir, en suma, la experiencia del sinsentido, no sólo como angustia o temor, sino también como enigma del deseo del otro. La pulsión, el modo como el viviente lo es sin programa y sin guía, obligado a rechazar para vivir como sujeto y a depender como defectuoso para vivir y satisfacerse, el conflicto pulsional y moral proveniente de esa paradójica relación del sujeto con la satisfacción, pues el conflicto es inherente a un objeto de la satisfacción que es a la vez sujeto, desde la madre, a la pareja o al amante, etc. Ese conflicto que impulsa en sus contradicciones a la elaboración inconsciente de la ambivalencia de nuestra relación con el otro, no puede ser borrado, está ahí y actúa en la dinámica inconsciente (en el inconsciente dinámico, que diría Freud; es decir, la subjetividad inconsciente), como bagaje con el que se construye ese mundo interno del que hablaba Stevens, que permite que el mundo externo no sea únicamente desolador. La memoria inconsciente es el espacio en el que el otro no sólo es odio- 
so o abandonador sino que se conserva como huella viviente de cada uno, de la forma que sea, satisfactoria o no.

El sujeto huye de sus defectos, no se forma principalmente con sus anhelos o proyectos sino con sus defensas, pues lo que quiere, por encima de todas las cosas, es defenderse de su miedo, aunque eso le lleve a la parálisis. A lo que nos enfrentamos en nuestra práctica es a los modos como cada sujeto se defiende, no sólo de su desamparo sino de su conflicto, de su contradicción radical como viviente, de su necesidad de conservar y a la vez de destruir, de amar y de odiar. La cuestión entonces no se resuelve con la exaltación idealista de la moral de la autosuficiencia, como hace, por ejemplo, M. Oakeshott, la cuestión será más bien tratar la defensa no tanto o no sólo como daño mutuo sino como anhelos de encuentros posibles, como anhelo de posibilidad. El conflicto pulsional no se puede borrar, lo que lo convierte en un dilema moral, pues entonces la satisfacción pulsional no se puede sostener en la simple ignorancia de la subjetividad ajena, y eso no sólo como temor sino también como enigma del deseo. En esa situación, el amor es un interrogante, una posibilidad.

\section{Denegación y huida de la experiencia}

Inestabilidad, dificultad para amar o soportar la soledad o la ausencia del otro, intolerancia a la pérdida, insensibilidad y superficialidad, carencia de intimidad, dependencia física y anaclítica, sin tomar en cuenta o incluso sin que exista vínculo amoroso o afectivo ni la pregunta sobre qué vínculo se quiere o se busca. La relación con los otros se hace así confusa por no responder a una elección amorosa sino a un uso maníaco o a una inhibición temerosa que evita tomar al otro como objeto de deseo y a la vez como sujeto que rompe la creencia en la objetividad. Esa confusión es correlativa a la falta de límite interno, que es el que pergeña el deseo en el mundo de los impulsos pulsionales, y que se fragua con la experiencia subjetiva del anhelo, la decepción, el encuentro, las pérdidas y los diversos avatares sensitivos, afectivos y morales, tales como la demanda, el amor, el rechazo, el temor, la angustia, la culpa. La experiencia subjetiva, marcada por los acontecimientos que suceden en las relaciones con los demás, mezcla, por tanto, de actos propios y ajenos, de actuaciones y padecimientos, es la memoria inconsciente, que produce el sentimiento de vivir, el sentimiento de que nuestra experiencia no está aún agotada. La denegación pretende borrar todo suceso, pues todo suceso es temible, de ahí que sea una huida de la experiencia misma, como si nada hubiese sucedido, puesto que lo sucedido está demasiado cercano a lo traumático y demasiado desprovisto de elaboración interna. Sorprende la falta de vida inconsciente, contradictoria, indecisa, no digo confusa, plural, ya que la dimensión inconsciente introduce por su propia elaboración otra escena, es otra escena, luego 
ORIGINALES Y REVISIONES

ya no hay una sola escena como la traumática, una escena fija e inmóvil, aniquiladora de la experiencia. La denegación es contraria a la experiencia, a veces aparece como única defensa, pero radical defensa contra la experiencia, buscando su anulación, en todo caso consiguiendo una especie de insensibilidad, de frialdad y de banalidad de los sentimientos, que necesita siempre el ruido del grupo.

De ahí que en esos casos más extremos encontremos una superficialidad afectiva y una vida inconsciente mucho más escasa que en la psicosis. Pues si, en efecto, el sujeto psicótico tiene dificultades para preservar los límites con el exterior, parece, sin embargo, dispuesto, valga la expresión, a sacrificar la realidad para sostener a su modo su propio mundo interno, un mundo interno atiborrado de interpretaciones de los otros. La relación intensa con el poder que sostiene el delirio psicótico es distinta en la denegación. En la denegación, percibir al otro en su facticidad es un modo de poseerlo, de controlarlo. Estar en el campo perceptivo es primordial, aunque a veces sea de modo persecutorio, y la ausencia es un temor, una angustia aniquiladora. De ahí lo acertado de la conocida frase de Hermann Broch: «El inconsciente es lo que resiste al poder», pues, en efecto, el inconsciente, la intimidad, es lo que escapa al poder, lo único que no capitula ante el poder. Se expresa entonces por el síntoma, por el conflicto moral y no necesariamente por la sumisión. «Resistir» es un buen término, resistir aunque fuera sin esperanza, es el reducto del sujeto del inconsciente, del sujeto marcado y determinado por su experiencia, sin querer borrarla con las fórmulas de la Fuerza colectiva, ya sea la Patria o el Estado.

Esta carencia de vida inconsciente favorece el mimetismo que tiene este tipo de comportamiento tan continuo y sin fisuras que se borra en su propio activismo o en su estéril circularidad, con un tipo de sociedad, como la actual, hipomaníaca, débil e insensible. Si es verdad que la época victoriana favorecía las histerias, mucho más esta nuestra de ahora no sólo favorece los trastornos del límite, sino que quienes los padecen de esa manera tan exclusiva, sin los recursos de la vida interna, parecen clones de este tipo de sociedad. El sujeto histérico puede contraponer a su época su propia respuesta inconsciente, en estos otros casos es como si se careciera de ella. Al no haber vida inconsciente, la otra escena según la calificación freudiana, el mundo se reduce a una única escena repetida cada día sin discontinuidad íntima, un continuиm sin límite interno que como tal continuum no se distingue del entorno. Ser camaleónico, se defiende de la angustia con el mero mimetismo, lo que le desacredita como sujeto.

\section{Carencia de la dimensión del cambio}

Sin límite interno, sin discontinuidad o quiebra, la propia dimensión del cambio, inherente al sujeto, desaparece. Así vemos que se presentan sin que precisen, ni 
muestren, ni se les ocurra la posibilidad de un cambio real en sus vidas, con un malestar difuso, a-histórico, incluso, a veces, no sólo les parece absurdo hablar de su supuesta historia, sino que muestran su malestar con cierta hostilidad. El cambio es, sin embargo, una dimensión, como digo, inherente a la subjetividad, sea al menos como lo imprevisible y lo inconmensurable (o no del todo previsible o conmensurable). Esa dimensión del cambio es correlativa a la dimensión moral que ha de decidir su respuesta a la demanda de los demás y ha de construir su propia demanda desde la distancia contradictoria con el otro, espacio de la ambivalencia, repito, ya que el otro es tanto objeto de satisfacción como sujeto deseante. Entre su reducción absoluta al estatuto de objeto de uso o su aparatosa dimensión persecutoria, el otro queda fuera del vínculo amoroso y moral. Si se desconoce el conflicto pulsional y la ambivalencia, se carece de criterio moral para decidir qué relación, cómo construirla desde la existencia real del otro y no desde la calumnia, y cómo en su caso preservarla del daño o, en todo caso, cómo en medio de la contradicción y de la ambivalencia entre amor y odio, aceptación y rechazo, mantener un criterio moral, condición de la hondura emocional, de la sensibilidad y de la diversidad del mundo y de sus personajes. Aceptar la existencia del otro no es coincidir con él. A veces la exaltación de la tolerancia suena a inercia o muerte intelectual y moral. Uno puede no tolerar lo que ve, pero acepta verlo y admitir en su propia indignación su existencia, sin tener que borrarlo del mapa, entre otras cosas porque no se puede.

La dimensión de cambio, o dimensión moral, se manifiesta por la desazón, la incertidumbre y el desacuerdo consigo mismo y con la época que le tocó vivir. No es añorar otra, ni negar el hecho de la actual, es simple desacuerdo moral con la tuya. La ideología de la resignación, como, por ejemplo, el genetismo o la doctrina de la predestinación, remiten el cambio a un agente exterior, sea el gen o la voluntad divina, que aniquila la dimensión subjetiva y moral del individuo. $\mathrm{Ni}$ sujeto, ni moral, es mero artificio desacreditado del poder.

\section{Dependencia anaclítica y falta de ambivalencia}

En este tipo de defensas tan primarias de las que hablamos a propósito de los trastornos del límite, presididas por la denegación, el rechazo no significa separación, sino paradójicamente dependencia y, por tanto, miedo. Es rechazo detenido al borde de su negación, de ese vacío, y entonces se busca sólo la posesión, creando esa bicefalia de rechazo y dependencia que crea relaciones muy superficiales desde el punto de vista del compromiso emocional, pero, sin embargo, muy persecutorias. En ocasiones, la agresividad persecutoria puede ser el escuálido resto de una subjetividad abortada. Decepcionados ante su confusa y apenas atisbada realidad interior y el evanescente sentimiento de realidad interna, incapaces 
ORIGINALES Y REVISIONES

entonces de fantasear escenas amorosas y afectivas sino sólo de poder, ejercido o padecido, únicamente si odian o se asustan parecen tomar realidad, como si el odio, el miedo y la agresividad fueran el único anclaje interpretativo con la realidad. No supone necesariamente un apartarse de la realidad; por el contrario, el realismo en estos sujetos es en ocasiones sorprendente cuando se les ve desde el flanco de su labilidad yoica. Por realismo entiendo su capacidad de adaptación a un escenario de poder, a su automática y servil adaptación a ese escenario, sea desde el entusiasmo sádico o la inhibición temerosa. El caso extremo de este tipo de adaptación adquiere la tonalidad inquietante de la perversión y en general de las llamadas personalidades narcisistas, sobre lo que luego volveremos.

Esa capacidad de adaptación física y superficial, va ligada a la desaparición de la ambivalencia. Sin la ambivalencia se puede querer algo y lo contrario a renglón seguido sin conflicto, ya que la ambivalencia proviene de la incorporación de la dimensión subjetiva al objeto. Es el caso, quizá extremo, del violador que tapa a su víctima con su chaqueta para que no se enfríe o el que cura con esmero la herida que ha infligido a su pareja. Ya en su Lehrbuch de Psiquiatría, Bleuler relacionaba muy acertadamente ambivalencia, represión e inconsciente, es decir, la dimensión conflictiva de la vida inconsciente o vida subjetiva. Sin ella, la agresividad y el sentimiento persecutorio, que parece el único posible, resaltan sobre un fondo depresivo o inerte, casi irreal. El sentimiento persecutorio que proviene de la debilidad de un vínculo afectivo hondo, conflictivo y vivo, crea un universo de complicidades superficiales encaminado a la desvalorización del otro, a protegerse de su persecutoria lejanía. No hay distancia, luego todo signo de la distancia está concebido como persecutorio, como si esa fuera la única forma de que el otro tome concreción y deje de ser un artefacto manipulable. En todos los casos, lo que parece claro que no opera es la ausencia del otro como anhelo, deseo, y sus consecuencias representativas: fantasías o silenciosas interpretaciones. Sin la capacidad de fantasear, la vida se empobrece y el mundo es sólo hostilidad y daño. El sujeto no puede reconocer la ausencia del otro, su pérdida (sea la madre o la pareja o quien fuere) como causa de su sufrimiento, por tanto, no puede construir lazos vivos entre la representación y el afecto, ya que no puede desplazar los afectos (efecto de la represión) sino sólo inmovilizarlos o, en general, denegarlos, como si no acontecieran. El otro así no vive en uno mismo, no tiene lugar ni espacio en la intimidad psíquica, el vínculo se ve entonces que es escuálido o, en todo caso, hostil y únicamente hostil, y la demanda es sólo, a lo más, reproche.

\section{Trastornos del límite y psicosis}

Por lo dicho hasta aquí se puede deducir que este campo de los trastornos del límite es extraordinariamente extenso y que por sus propias características es difí- 
cil de aprehender. De hecho, sus fenómenos clínicos, aunque quepa localizar un núcleo básico en torno al predominio de la denegación, son muy diversos, y van desde los más cercanos a la neurosis, a los comportamientos o fenómenos que hacen pensar en la psicosis, pasando por ese campo extraño de los fenómenos perversos y psicopáticos. Hay que tener en cuenta que la denegación está de hecho más presente en la neurosis que en la psicosis, mejor dicho, está siempre presente en la neurosis, aún en connivencia con la represión e incluso la elaboración inconsciente, mientras que parece prácticamente inexistente en la psicosis como tal, cuando la psicosis aparece. Incluso cabría decir que al sujeto psicótico, en cuanto psicótico le es propia la dificultad para denegar. El psicótico, incapaz para la mentira, tal como definía Epicteto la locura, es por ello inepto para la denegación. La denegación, presente en la neurosis, se convierte en arrasadora cuando es la única defensa, y entonces el denegador no es alguien que miente sino que es mentira. Es lo que tantos clínicos han intentado formular, desde el «como si» de Helen Deutsch al sentimiento de irrealidad al que todo aquel que ha trabajado este asunto siempre se refiere, y que muchos terminaron formulando como falso self.

Pero este sentimiento de irrealidad tiene una raigambre mayor que la mera manifestación del falso self, proviene de un sentimiento de vacío y desamparo que fue como apareció el conflicto pulsional, la experiencia de un estar vivo sin recursos para ello. Esta congoja reaparece cada vez que surge una renovación de esa angustia ante un acontecimiento actual, sea algo oído o visto, que renueva o repite esa angustia primaria, traumática, que da al sujeto viviente la sensación de irrealidad o un sentimiento de intensa extrañeza. Esta conexión entre lo oído o visto, en todo caso sentido, y la angustia primitiva se puede llamar regresión. No sé si es así como Freud entiende la regresión. A mi entender, la regresión no es una defensa, sino lo que sobrepasa las defensas, ya que se da cuando las defensas se desestabilizan, cuando el orden del mundo y los modos de comprensión se extravían a causa de la quiebra de las representaciones facilitadas o conjunto de representaciones familiares, y viene entonces ese extrañamiento radical o primario, esa reaparición de la primera experiencia traumática con desamparo y pánico. Por eso creo que tras el sentimiento de irrealidad, está el fondo melancólico del que tantos clínicos han hablado y que hay que entender en sentido fuerte: regresión al sinsentido, al vacío libidinal, a la soledad y al desamparo.

Ahí pueden darse fenómenos alucinatorios, sin que eso implique necesariamente una psicosis. El fenómeno alucinatorio puede deberse a esa sensación de extrañamiento que da al otro un tipo de presencia avasalladora, aniquiladora de una realidad propia y diferenciada, debido a la dificultad o incapacidad de desplazamiento. El desplazamiento es posible por la represión, pues al reprimirse la representación, la carga de afecto queda disponible para vincularse a otras representaciones. Al no haber desplazamiento o al prevalecer otro tipo de defensas más 
ORIGINALES Y REVISIONES

primarias como la disociación persecutoria del objeto, la carga del afecto no está disponible y se adhiere a una representación que toma en ese momento carácter absoluto y por tanto alucinatorio. Estos fenómenos alucinatorios pueden aparecer, por ejemplo, en períodos de duelo o de muertes inesperadas, también en situaciones de pérdidas muy traumáticas por estar muy ligadas a la angustia de percepción, en situaciones de trauma (es decir, de carga sin representación definida o continente), también en el trance transferencial que se produce porque la transferencia moviliza y favorece experiencias arcaicas alucinatorias conforme a las cuales el psicoanalista puede aparecer como objeto único y absoluto con ese carácter disociativo y la consiguiente aniquilación de la propia realidad interior.

Pero también pueden aparecer con una constancia mayor. Delirio o alucinación es, por ejemplo, que un hombre todavía joven ande buscando los indicios de la presencia de extraños en su pequeño apartamento ante el temor a ser controlado en su intimidad, o ese temor al contagio, que no bastaría con calificar de obsesivo, creyendo que si da la mano a un amigo se verá contaminado de una especie de sexualidad sucia y pegajosa que él a su vez transmitirá si da la mano a otro, a mí por ejemplo, o que teme que restos de semen le sean arrojados o simplemente caigan de las ventanas. Digo «creyendo» porque este hombre sabe que son ideas que se le imponen a pesar de su inverosimilitud, sin tener la certeza de su veracidad sino más bien lo contrario, sabedor de que no es así, de que no se corresponden con la realidad aunque no pueda librarse de ellas y terminen constituyendo su mundo «interno».

¿Cómo tratar lo alucinatorio? Por algún tipo de desplazamiento que permita rehacer el sentido del mundo, inscribir la pérdida y diversificar a los otros y, por consiguiente, romper con la escena fija y única, tanto traumática como incestuosa, sin distancia ni vida inconsciente. El inconsciente es siempre «otra escena». Ni hay un solo acto, ni un solo rasgo del otro, tratamos siempre con una diversidad que da a los demás su carácter de enigma, incluso de perplejidad. Hay un modo menos solitario de quebrar la presencia del otro como absoluto, es la creencia. La creencia es, como la llamó Blumenger, una «metaforización de lo absoluto». Por medio de la creencia se construye la grupalidad y la pertenencia. Es la condición de la comunidad. La creencia no trata de la existencia, si así fuera no sería creencia. La creencia está en el lugar de la epojé, pues sustituye la nada de la consciencia por la convicción de la comunidad, y la existencia del otro por su figura atributiva.

En la psicosis, por el contrario, no hay creencia. Este fue sin duda un gran atisbo freudiano, el calificar la psicosis como Unglauben. Por eso dije anteriormente que el psicótico no es creyente y que por esa razón es quien soporta la existencia de Dios, el terror de su omnipotencia y de su omnividencia, el terror, en suma, de lo absoluto. No son creyentes, están expuestos a la certeza. Si la creencia es descarga de lo absoluto, la certeza carece de esa descarga y, por ello, es mero terror. El psicótico soporta el terror de la existencia de Dios, por eso carece de iglesia, la iglesia 
es descarga de absoluto, es creencia, no certeza, que se resuelve en convicción institucional. La creencia siempre es en grupo, y así la religión institucional como vínculo colectivo terrenal sirve para descargarse de absoluto. El psicótico está solo ante lo absoluto, Dios es real, no metafórico, está siempre ahí, omnipotente y omnividente, y el daño que inflige es igualmente absoluto y letal. Delira para consolarse de sus alucinaciones, pero a la vez ese delirio no tiene otro soporte que la alucinación. De ahí que cuando un delirante tenaz, por ejemplo, un paranoico, vira hacia la religión, intenta una vía de salida, un modo de entrar en una comunidad de creyentes que opera, por tanto, como metaforización de lo absoluto. De ahí que normalmente esos intentos terminen en el psicótico empedernido en un fiasco.

En la psicosis, el delirio es el modo de construir una pertenencia y una inclusión en lo histórico, en la filiación sexuada. Se puede entender entonces como un modo de desplazar la representación y descargarse de la carga de objeto adherida a ella y así incluir lo alucinatorio en un tipo de historia y de ese modo disolverlo. La amenaza parece preferible a la inanición libidinal. Es un modo de construir una realidad aunque sea a costa de romper con la realidad grupal, la basada en el sistema de creencias. Puesto que en cuanto psicótico no le está permitida la denegación, esa extrema sensibilidad ante el acontecer de la vida le obliga a una constante actividad mental de recreación interminable. Es lo que Schreber formuló como «empuje a pensar», insidioso, terrible e imparable.

La presencia de la denegación no excluye radicalmente la posibilidad de delirar. Incluso comprobamos en nuestra clínica diaria que un psicótico no es psicótico todo el tiempo, solemos decir de alguien, por ejemplo, «hoy está psicótico». Si fuera psicótico todo el tiempo, sólo tendría como salida el estallido de un delirio imparable, des-metaforizado, o la absoluta inanición, es decir, la muerte en uno u otro caso. El delirio viene siempre en ayuda de una fragilidad identificatoria, de una angustia traumática, de una contención precaria de la agresividad y, en suma de una pérdida, o hemorragia de vida interior. Si no permite descansar en algún sentido o en alguna significación, su estallido es especialmente destructivo.

Volviendo sobre la denegación, vemos que en estos casos extremos de trastornos del límite, sucede que el temor y una inhibición incapacitadora les impide el trato social y el juego de la comunicación. Estropean las palabras de tanto buscarlas, su discurso es repetitivo y monótono. La fragilidad fantasmática interna, la incapacidad para fantasear, hace que algunos pensamientos se proyecten hacia fuera como si los vieran u oyeran desde fuera, como si la escena fantasmática se fraguara en ese instante escueto y frío, sin discontinuidad. No es un delirio construido, es un esbozo delirante que intenta una representación psíquica. Como en el caso del hombre señalado más arriba, es un intento de supervivencia que no construye una realidad propia, sino que toma un esbozo o fragmento externo para darse realidad y sentir que existe. Pueden pasar desapercibidos incluso para ellos mis- 
ORIGINALES Y REVISIONES

mos. Este encuadre vacío es lo que llevó a Bergeret a hablar de un estado depresivo de fondo con ese lastre corporal y regresivo que les hace torpes, anaclíticos y adheridos sin poder crear una relación fluida o viva. Ese fondo melancólico, que tanto indagó Bergeret, y el sentimiento de irrealidad, subrayado por todos, proviene de un desamparo tan radical que no es sólo la dependencia del infans, sino una especie de condena melancólica, como si su venida al mundo careciera de transmisión y fuera una funesta casualidad, condenados entonces a no tener lugar alguno en los otros, sin historia y sin poder inventársela. La filiación sería un mero hecho externo, no una vivencia histórica de transmisión de vida. El llamado falso self tiene una raíz aún más seca: no sólo ellos se sienten falsos sino la vida misma, y si la vida es una ficción, los impulsos de la pulsión no tienen otro destino que el paso al acto, la inhibición más radical, el mutismo del superviviente o el grito falto de demanda (a no ser que como en las llamadas personalidades narcisistas consigan adentrarse por la senda de la manipulación y de la admiración conseguida en compensación de la muerte interior).

A veces una extraordinaria debilidad o pobreza de elaboración hace que puedan aparecer como débiles psíquicos y mentales, y siempre uno se sorprende de que puedan hacer en muchos casos su trabajo, a veces incluso técnicamente complejo. Parecen espectros en su aislamiento afectivo, sacudidos por la hostilidad y el miedo, pero sin conseguir una mínima interpretación eficaz del otro. Se les da de lado porque ellos mismos se sienten inexistentes e invisibles. «Me siento a la mesa familiar y nadie me ve», decía un sujeto anclado en lo que él mismo llama su bloqueo permanente. Tiene su «teoría» que repite una y otra vez de modo cansino y automático: «Si me muevo entonces mi padre va a morir de un infarto, mi padre es puro y neto, y entonces que nadie se mueva, que nadie diga nada, si digo algo es que lo estoy matando». Y así día tras día, inmutable, a-histórico. Sólo muy recientemente le oí usar el verbo en pasado, con lo que quizás esa distancia verbal pueda significar el tiempo de la respiración psíquica.

¿Cómo se sostiene en esa inercia psíquica sin que tampoco acontezca una «exoactuación» destructiva? Parecen sobrevivir con el mínimo gasto psíquico. Dado su estado de pobreza de recursos, prefieren no viajar ni cambiar de ambiente. En ocasiones, la hipocondría parece la forma de crear un espacio de preocupaciones que parece suplir o compensar el terror de la muerte interior, su torpe y frágil investimiento libidinal del cuerpo.

\section{El debate sobre las personalidades narcisistas y la cuestión de la perversión}

Los trastornos del límite se caracterizan en general, tal como venimos diciendo, por esa falta de distancia subjetiva y de vida interna con predominio de la 
denegación que borra las preguntas sobre quién se es o qué se quiere o de dónde se proviene o por quién se es amado, si lo fuere, preguntas más presentes en las psicosis (las primeras, que dan lugar a los delirios específicos de filiación y de salvación) y en las neurosis (las segundas). Pero los hay para quienes la denegación les hace eficaces manipuladores de los sentimientos o debilidades ajenas: desde los más actuadores, o «exoactuadores» como algunos los nombran, a los más certeros en el comportamiento estratégico de conseguir, de los demás, admiración y dependencia. Ellos son los genuinos representantes de las llamadas «personalidades narcisistas» $\mathrm{O}$ «trastornos narcisistas de la personalidad», que de ambas maneras se conocen, por mucho que la tan traída y llevada personalidad sea un hueso duro de roer. Es asunto, en todo caso, de indudable interés clínico, dada la frecuencia del cuadro. Se esté o no de acuerdo con las «elucubraciones teóricas» de Kernberg, no cabe duda de su soltura clínica a la hora de describirlo. Tiene muchos textos y pasajes al respecto. Elijo sólo uno que me parece pertinente. Dice así: «Los rasgos sobresalientes de las personalidades narcisistas son la grandiosidad, la exagerada centralización en sí mismos y una notable falta de interés y empatía hacia los demás, no obstante, la avidez con que buscan su tributo y admiración. Sienten gran envidia hacia aquellos que poseen algo que ellos no tienen, o que simplemente parecen disfrutar de sus vidas. No sólo les falta profundidad emocional... sino que además sus propios sentimientos carecen de diferenciación, encendiéndose en rápidos destellos para dispersarse inmediatamente. En particular, son incapaces de experimentar auténticos sentimientos de tristeza, duelo, anhelo y reacciones depresivas, siendo esta última carencia una característica básica de sus personalidades. Cuando se sienten abandonados o defraudados por otras personas, suelen exhibir una respuesta aparentemente depresiva, pero que, examinada con mayor detenimiento, resulta ser de enojo y resentimiento, cargado de deseos de venganza, y no verdadera tristeza por la pérdida de una persona que apreciaban» (p. 206).

La descripción es excelente. Kohut diría que inespecífica, por lo que pretendió separar estos casos de los llamados «estados fronterizos», pero esa distinción, en el caso de Kohut, no esclarece mucho, ya que si en efecto estudia las maneras arcaicas de la defensa narcisista tampoco aclara mucho la formación del narcisismo como diferenciado del autoerotismo, como tampoco lo hace para distinguir esos «estados fronterizos» de la esquizofrenia. Esto revela una vez más que poner el acento en la clasificación diagnóstica no es más que un debate estéril. Los trastornos del límite son trastornos que de uno u otro modo, y en cuanto que se refieren a lo más primario del vínculo afectivo, a todos nos atañen. 


\section{BILIOGRAFÍA:}

(1) BERGERET, J. (1974), La personalidad normal y patológica, Barcelona, Gedisa, 1996.

(2) Bergeret, J., La dépression et les états limites, París, Payot, 1975.

(3) Blumenberg, H. (1981), La legibilidad del mundo, Madrid, Tecnos, 2000.

(4) Donnet, J. L.; Green, A., L'enfant de ça. Psychanalyse d'un entretien: psychose blanche, París, Minuit, 1973.

(5) Freud, S. (1933), «Nuevas lecciones introductorias al psicoanálisis», en Obras Completas 8, Madrid, Biblioteca Nueva, 1974.

(6) Freud, S. (1926), «Inhibición, síntoma y angustia», en Obras Completas 8, Madrid, Biblioteca Nueva, 1974.

(7) GeHlen, A. (1974), El hombre, Salamanca, Sígueme, 1980.

(8) Joyce, J., Retrato del artista adolescente, Barcelona, Argos Vergara, 1980.

(9) Horkheimer, M.; Adorno, T. (1944), Dialéctica de la ilustración, Madrid, Trotta, 1994.

(10) KANT, E. (1798), Antropología, en sentido pragmático, Madrid, Alianza, 1991

(11) Kant, E. (1790), Crítica del juicio, Madrid, Espasa-Calpe, 1977.

(12) Knight, R. P., «Boderline States», en Lowenstein, R. M., Drives Affects, Behavior, Nueva York, Intern, Univ. Press, 1953.

(13) Koнut, H. (1971), Análisis del Self: El tratamiento psicoanalítico de los trastornos narcisistas de la personalidad, Buenos Aires, Amorrortu, 1977.

(14) Mongardini, C., Miedo y sociedad, Madrid, Alianza, 2007.

(15) PatoČKA, J. (1975), Ensayos heréticos, Barcelona, Península, 1988.

(16) PEREÑA, F., El hombre sin argumento, Madrid, Síntesis, 2002.

(17) PereñA, F., «Cuerpo y subjetividad: acerca de la anorexia», en Revista Española de Sanidad Pública, 81, 5, 2007, Madrid.

(18) Chabert, C.; Brusset, B.; Brelet-Foulard, F. (1999), Neurosis y funcionamientos límite, Madrid, Síntesis, 2001.

(19) KeRnBerg, O. (1975), Desórdenes fronterizos y narcisismo patológico, Barcelona, Paidós, 1979.

* Francisco Pereña, psicoanalista.

Correspondencia: C/ Hortaleza, 106, 2. ${ }^{\circ}$ dcha, 28004, Madrid.

** Fecha de recepción: 14-VII-2008 (aceptado el 20-VIII-2008). 